\title{
CAN score- a boon to resource limited settings
}

\author{
Geetha M. ${ }^{1}$, Kiran B. ${ }^{2}$, Santosh. S. ${ }^{3}$, Rangaiah V. ${ }^{4}$, Himabindu T. ${ }^{5}$, Pavan Raj ${ }^{6}$, Angel L.D. ${ }^{7}$ \\ ${ }^{1}$ Dr. Geetha M, Assistant Professor, ${ }^{2}$ Dr. Kiran B, Professor \& HOD, ${ }^{3}$ Dr. Santosh. S, Professor, ${ }^{4}$ Dr. Rangaiah V., Senior \\ Consultant, ${ }^{5}$ Dr. Himabindu T., Resident, ${ }^{6}$ Dr. Pavan Raj, Resident, ${ }^{7}$ Dr. Libni D. Angel, Resident, all authors are \\ affiliated with Department of Pediatrics, East Point College of Medical Sciences and Research Centre (EPCMSRC), \\ Bengaluru, Karnataka, India.
}

Corresponding Author: Dr Geetha M., Assistant Professor, Department of Pediatrics, East Point College of Medical Sciences and Research Centre (EPCMSRC), Bengaluru, Karnataka, India. E-mail:gee_festoon@yahoo.co.in

\begin{abstract}
Introduction: Fetal Malnutrition is one of the major determinants of neonatal outcomes, especially in under privileged communities. Assessment may be tedious, expensive and often eating into resources limiting its effective management. CAN scoring emerging as a promising simple and cost effective tool needs validation before wide spread adoption. Materials and Methods: We carried out a Prospective Study of 3 months duration between $1^{\text {st }}$ November 2018 and $31^{\text {st }}$ January 2019 at our Hospital, a tertiary care centre with neonatal intensive care unit (NICU) in South India. Results: Total number of newbornin our study was 104 . The incidence of malnutrition according to CAN Score is $29.8 \%$, Ponderal Index 12.5\%, Weight for Gestational Age is $13.5 \%$ and Body Mass Index is $14.4 \%$. The Sensitivity, Specificity and Positive Predictive Value of CANS are $83.87 \%, 79.45 \%, 63.41 \%$, which are high and are statistically Significant. Conclusion: CAN Score appear to be a Simple and Cheap Tool to accurately assess Neonatal Malnutrition.
\end{abstract}

Keywords: Fetal malnutrition, CAN score, Ponderal index

\section{Introduction}

The term fetal malnutrition was coined by Scott and Usher in 1966 which is defined as soft tissue wasting at birth and failure to acquire quantum of fat $\&$ muscle mass during intrauterine growth [1]. The terms SGA, IUGR, LBW are not synonymous. Fetal malnutrition is a major determinant of Neonatal Outcomes especially in under privileged communities [2]. About 40\% have Intellectual and Neurological handicap in the future.

The assessment of fetal malnutrition may be tedious, expensive and often eating into resources limiting its effective management. The common methods of assessment are based on Anthropometry, Proportional indices and Clinical assessment [3].

CAN scoring, a clinical assessment tool described by Metcoff has since its inception been tried with promising results with few studies in India, needing validation before wide spread adoption. [4-7] (figure 1). The aim of this study is to identify the incidence of fetal malnutrition and to compare CAN score with other assessment tools.

Manuscript received: $10^{\text {th }}$ April 2019

Reviewed: $20^{\text {th }}$ April 2019

Author Corrected: $25^{\text {th }}$ April 2019

Accepted for Publication: $30^{\text {th }}$ April 2019

\section{Material and Methods}

Setting: Department of Paediatrics, EPCMSRC, A tertiary care centre with NICU

Type of study: Prospective pilot study conducted for 3 months duration from $1^{\text {st }}$ November 2018 to $31^{\text {st }}$ January 2019

Sample collection: Patient records like Antenatal (ANC) cards, Delivery notes, Neonatal records and Inpatient case sheets. Anthropometric details measured were Birth weight and Length at time of birth. Ponderal index (PI), Body mass index (BMI), Weight for Gestational Age (GA) and CAN score were calculated as per standard formula, percentile chart and Metcoff chart respectively. CAN scoring was done by a single observer between 24 to 48 hours after birth.

\section{Inclusion criteria}

- All Consecutive Term > 37 weeks

- Delivered inborn

Exclusion Criteria

- Congenital anomalies

- Twins

- Preterm neonates 


\section{Original Research Article}

Statistical methods: Statistical analysis was done using Software MS Office and SPSS. The Statistical formulas were Pearson correlation coefficient $r$, Chi square test, screening validity. Sensitivity, specificity, positive and negative predictive value were calculated.

Ethical consideration: Institutional Ethics Clearance (IEC) approval was obtaine.

\section{Results}

The total number of newborns fulfilling the inclusion and exclusion criteria and included in the study was 104 ( $\mathrm{n}=104$ ). Of the analysed 104, 59 were female and 45 were male. There was a slight female preponderance which is statistically significant.

On analysis of the mothers it was found Primigravidae were 38 , multipara ( 3 or $>$ ) were 31 with maternal age average 25.34 years, median 25 years and mode being 22 years. Mothers having history of previous abortions were 6 and previous child deaths were 5. Maternal illness noted was GDM in 16, PIH in 6, Hypothyroidism in 12.

Table-1: Comparison of proportional indices of various anthropometric measurements

\begin{tabular}{|c|c|c|c|c|c|}
\hline Indices & Weight & Length & BMI & Ponderal index & CANS \\
\hline MEAN & 2.887 & 47.78 & 12.56 & 2.866 & 27.567 \\
\hline STDV & 0.433 & 2.697 & 1.722 & 2.123 & 3.355 \\
\hline MEDIAN & 2.900 & 48.00 & 12.75 & 2.640 & 28 \\
\hline 1Q & 2.650 & 46.00 & 11.60 & 2.440 & 25 \\
\hline 3Q & 3.215 & 50.00 & 13.61 & 2.900 & 30 \\
\hline MODE & 3.400 & 50.00 & 12.80 & 2.700 & 29 \\
\hline
\end{tabular}

When analyzing the total 104 newborns, the anthropometric details noted were mean birth weight of $2.88 \mathrm{~kg}\left(2.88^{+} .0 .43\right)$, and length $47.79 \mathrm{~cm}\left(47.79^{+}{ }_{2} 2.69\right)$. The proportional indices were BMI $12.56\left(12.56^{+}\right.$.1.72) and PI 2.86 (2.86 ${ }^{+}$. 2.12). The CAN score was $27.56\left(27.56^{+}{ }_{-3} 3.35\right)$ (Table 1)

Table-2: Malnourished assessed by various tools

\begin{tabular}{|c|c|c|c|}
\hline Parameter & Normal & Malnourished & Incidence \\
\hline BW & 87 & 17 & $16.3 \%$ \\
\hline GA & 90 & 14 & $13.5 \%$ \\
\hline PI & 91 & 13 & $12.5 \%$ \\
\hline BMI & 89 & 15 & $14.4 \%$ \\
\hline CANS & 73 & 31 & $29.8 \%$ \\
\hline
\end{tabular}

The data was analysed for fetal malnutrition with the predetermined cut offs and the results were as follows. Out of 104 neonates, 17 were of low birth weight $(2.5 \mathrm{~kg})$ which is $16.3 \%$. 14 were small for gestational age $(13.5 \%)$. About 13 (12.5\%) neonates had Ponderal index below 2.2, low BMI was seen in 15 babies (14.4\%). Around 31 newborns were malnourished according to CAN scoring which is $29.8 \%$. (Table 2)

Table-3: Chi Square Test

\begin{tabular}{|c|c|c|c|c|}
\hline CAN & Ponderal index & BMI & Birth weight & Gestational age \\
\hline 73(86.00) [1.97] & 91(86.00) [0.29] & 89(86.00) [0.10] & $87(86.00)[0.01]$ & $90(86.00)[0.19]$ \\
\hline $31(18.00)[9.39]$ & 13(18.00) [1.39] & 15(18.00) [0.50] & $17(18.00)[0.06]$ & $14(18.00)[0.89]$ \\
\hline
\end{tabular}

The Chi Square statistic is 14.7804 . The p- value is 0.005179 .

Chi square test was performed and the assessment of malnutrition by CANS with other methods was statistically very significant, $\mathrm{p}=0.0051(\mathrm{p}<0.01)$. (Table 3) 
Table-4: Sensitivity, specificity, predictive values and accuracy

\begin{tabular}{|c|c|c|c|c|c|}
\hline Parameter & BW & GA & PI & BMI & CANS \\
\hline Sensitivity & 73.68 & 85.71 & 44.44 & 53.33 & 83.87 \\
\hline Specificity & 80.00 & 78.89 & 71.58 & 74.16 & 79.45 \\
\hline PPV & 45.16 & 38.17 & 12.90 & 25.81 & 63.41 \\
\hline NPV & 93.15 & 97.26 & 93.15 & 90.41 & 92.06 \\
\hline Accuracy & 78.85 & 79.81 & 69.23 & 71.15 & 80.77 \\
\hline
\end{tabular}

Sensitivity, specificity and predictive values of each of the tools were calculated and compared (Table 4) CAN score had the highest accuracy of $80.77 \%$ with high sensitivity of $83.87 \%$, specificity of $79.5 \%$, positive predictive value of $63.41 \%$ and negative predictive value of $92.06 \%$.

According to GA, accuracy is $79.81 \%$, highest sensitivity of $85.71 \%$, specificity of $78.89 \%$, positive predictive value of $38.17 \%$ and highest negative predictive value of $92.06 \%$. BW had an accuracy of $78.85 \%$ with sensitivity of $73.68 \%$, specificity of $80 \%$, and positive predictive value of $45.16 \%$ and negative predictive value of $93.15 \%$.

According to PI, sensitivity of $44.44 \%$, specificity of $71.58 \%$, lowest positive predictive value of $12.9 \%$, negative predictive value of $93.15 \%$ had lowest accuracy of $69.23 \%$. BMI has a sensitivity of $53.33 \%$, specificity of $74.16 \%$, positive predictive value of $25.81 \%$, negative predictive value of $90.41 \%$ and accuracy of $71.15 \%$.

\section{Discussion}

Low birth weight is a major public health problem in India, incidence as high as $30 \%$, whereas in developed countries it is only 5-7\% [1]. Fetal malnutrition defined by Scott \& Usher in 1966 is a well established entity whose assessment can be done by various methods $[2,3]$.

A detailed knowledge of Fetal malnutrition is important to understand clinical problems, such as inutero growth restriction, fetal macrosomia and nutritional needs of the preterm infant. The growth of the fetus which is extremely rapid accounts for a significant fraction of the nutrients required by the fetus throughout gestation. Fetus is not a true parasite as it extracts only $2-4 \%$ of the nutrients reaching it from the placenta whereas $96 \%$ to $98 \%$ being returned to the placenta and maternal circulation [8]. Nutrition of the fetus depends on extraction, nutrient composition of the umbilical blood, flow rate and the capacity to utilize the extracted nutrients [9].

The classification systems for intrauterine growth retarded babies mostly are based on observed birth weight below the $3^{\text {rd }}$ or $10^{\text {th }}$ percentile for gestational age using various growth curves [10]. But none of the described classification system identifies fetal malnutrition. Fetal malnutrition is a term coined by Scott and Usher, which indicates a clinical state that may be present irrespective of birth weight, gestational age (AGA), intrauterine growth retardation (IUGR) or small for gestational age (SGA) categories [1].
The clinical manifestations of fetal malnutrition depend in part on when it began during gestation [10] Malnutrition beginning early in the second trimesterlength, head circumference and weight are significantly reduced.

a) Malnutrition beginning early in the third trimesterlength and head circumference are less affected, but are small and underweight with some loss of subcutaneous tissues and muscle.

b) Malnutrition- late in the third trimester-significantly underweight for gestational age with obvious loss of subcutaneous tissue, but with length and head circumference within normal range.

CAN scoring is the clinical assessment of nutrition described by Metcoff in 1994 to detect the fetal malnutrition done by readily detectable superficial signs. There are 9 clinical signs with eachscored from 1 to 4 , total ranging from 9 to 36 . The clinical presentation of fetal malnutrition varies based on the timing of gestation, while other anthropometric measurements may or may not be affected [5]. CAN score is advantageous to assess fetal malnutrition as it can most accurately measure subcutaneous fat and malnutrition as compared to other tools, it doesn't need any special equipment or formula to calculate and it is a good clinical index for predicting the neuro developmental outcome of infants with fetal malnutrition $[3,7]$. Scores less than or equal to 24 are taken as clinical evidence of malnutrition, which is occurring in utero i.e. Fetal Malnutrition [5]. 


\section{Original Research Article}

In his study, Jack Metcoff observed that $95 \%$ of AGA babies had a score greater than 24. More than $54 \%$ of SGA babies were malnourished, but $46 \%$ SGA babies had a score greater than 24. 5.5\% AGA babies were fully grown but were malnourished. A large error in classification would occur if SGA or IUGR were considered synonymous with fetal malnutrition and if all AGA babies were considered adequately nourished.

Man Mohan et al defined SGA as those with PI falling short of $10^{\text {th }}$ percentile for their gestational age so in a term infant PI $<2.25$ should be an indicator of intrauterine undernutrition. Ponderal Index relies on the principle that length is spared at the expense of weight during period of acute malnutrition.

Weight and length velocities may be proportionately impaired so infants with chronic insult in utero may be misclassified by PI. When CAN score was compared with Ponderal Index it gave a sensitivity of $44.44 \%$ and specificity of $71.58 \%$ in the present study.

The incidence of fetal malnutrition by CAN scoring in our study is $29.8 \%$ and the significant difference noted when compared to other tools of assessment in our study is similar to other studies, reemphasizing the importance of differentiating fetal malnutrition from SGA, IUGR [2-7]. Also CAN score have high accuracy and sensitivity and specificity when compared to other tools. This is similar to findings of previous studies $[3,7]$.

The incidence of fetal malnutrition in our study is $29.8 \%$. Incidence of FM according to various other Indian studies are Soundarya et al is $24 \%$, Abhaykumar Dhanorkar et all [12] is $32.29 \%$,Vikram Singhal et al [2] is $17.5 \%$, Naveen Sankhyan et al [13] diagnosed 27.97\% malnourished neonates and Adebami et al [14] detected $18.8 \%$ malnutrition by CANSCORE.

Higher percentage of FM in some studies may be explained by low socio economic condition of the mothers. According to Metcoff study, incidence was only $10.9 \%$, since this study was done in a developed country.

A total of 13 babies had a ponderal index $<2.2$ and sensitivity of PI in detecting FM was low (44.44\%). Cole TJ et al [17] found that the Ponderal index is not appropriate for measuring intrauterine malnutrition, as it fails to adjust for length at all gestations. About 16.3\% were malnourished according to birth weight measurements which accounts for $73.68 \%$ sensitivity which is much less than CANS scoring $(83.87 \%)$.
If we consider weight as the only criteria for assessing nutritional status, there is probability of missing malnourished babies in AGA category and over diagnosing well nourished babies in SGA category. In Conclusion, fetal malnutrition as assessed by CAN score is nearly $30 \%$ as compared to all other tools around $15 \%$. CAN Score has the highest accuracy with high sensitivity, specificity and negative predictive value. Limitations of our study are as follows. It is a hospital based pilot study with a small sample size. We have not excluded newborns of mothers with illnesses unlike some other studies.

\section{What this studyadds to existing knowledge?}

The broad understanding and lessons learnt from this study is that Fetal malnutrition is grossly inadequately assessed in our country though it impacts paediatric health. CAN score is a simple and cost effective tool and should be promoted for wide spread adoption.

Contribution by authors: I would like to thank our professor for the constant support and motivation for the study. I appreciate the contribution from the residents in data collection and analysis. I would like to thank my better half for all his support in manuscript preparation.

Funding: Nil, Conflict of interest: None initiated, Perission from IRB: Yes

\section{References}

1. Scott KK, Usher RH. Fetal malnutrition: Incidence, causes and effects. Amer J Obstetr. 1966; 94 (7): 951-63.

2. Vikram singhal, Prashanth Agal, Nutan Kamath. Detection of Fetal Malnutrition by CAN score at birth and its comparison with other methods of determining Intrauterine Growth. IndianJournal of Clinical Practice. April 2012;22 (11):576-82

3. Soundarya M, Basavaprabhu A, Raghuveera K, et al. Comparative Assessment of Fetal Malnutrition by Anthropometry and CAN Score. Iran J Pediatr. 2012 Mar; 22 (1):70-6.

4. Vishwanath Machakanur, Sudha Rudrappa. A Simple Screening-Tool for Fetal-Malnutrition at Birth: A Comparative Study of Clinical Assessment of Nutritional Status (CANS) versus others. Journal of Evolution of Medical and Dental Sciences 2014; Vol. 3, Issue 29, July21; Page: 8027-8032, DOI: 10.14260/ jemds $/ 2014 / 3007$. 


\section{Original Research Article}

5. Metcoff J. Clinical assessment of nutritional status at birth. Fetal malnutrition and SGA are not synonymous. Pediatr Clin North Am. 1994 Oct;41(5):875-91.

6. Varahala AM, Chidugulla SK, Pathuri NK. Assessment of foetal malnutrition by CANSCORE and comparison with anthropometric attributes-a tertiary care centre experience. IOSR Journal of Dental and Medical Sciences 2015;14 (10):07-12.

7. Waghmare $\mathrm{P}$, Balpande $\mathrm{N}$ D, Lakhkar B B. Assessment of fetal malnutrition by can score. PediatricOncall Journal [serial online] 2012 [cited 2012 January 1]; 9. Art \#1. Available From: http://www. pediatriconcall.com/pediatric-journal/View/fulltext arti-cles $/ 453 / \mathrm{J} / 0 / 0 / 89 / 0$

8. Apte SV, Iyengar L. Composition of the human foetus. Br J Nutr. 1972 Mar; 27(2):305-12.

9. Georgieff MK, Sasanow SR. Nutritional assessment of the neonate. Clin Perinatol. 1986 Mar;13 (1):73-89.

10. Singh M.Disorders of weight and gestation. In : Care of the Newborn, $7^{\text {th }}$ ed. New Delhi, Sagar Publications : 2010: 234-25

11. Hill RM, Verniaud WM, Deter RL, et al. The effect of intrauterine malnutrition on the term infant: a 14 year prospective study. Acta Pediatr Scand. 1984;73(4): $482-7$.
12. Dr Abhaykumar Dhanorkar, Dr Prashant Bagdey, Dr Arun Humne. Detection of Fetal Malnutrition at birth by clinical assessment of nutritional status score. Health sciences: An International Journal. 2014; 4 (1):1-5.

13. Sankhyan N, Sharma VK, Singh S. Detection of fetal malnutrition using "CAN score". Indian J Pediatr. 2009 Sep;76 (9):903-6. doi: 10.1007/s12098009-0196-9. Epub 2009 Nov 4.

14. Adebami OJ, Owa JA, Oyedeji GA, et al. Prevalence and problems of foetal malnutrition in term babies at Wesley Guild Hospital, South Western Nigeria. West Afr J Med. 2007; 26(4):278-82.

15. Liladhar Kashyap, Rashmi Dwivedi. Detection of Fetal malnutrition by clinical assessment of nutritional status score (CAN SCORE) at birth and its comparison with other methods of determining intrauterine growth. Pediatric On Call Journal. January 2006;(3): 1.

16. Taylor D. Nayak US. CAN score-Assessment of nutritional status of newborns. J Obstetric Gynecol. 2002;52 (1):76-8.

17. Cole TJ, Henson GL, Tremble JM, et al. Birthweight for length: ponderal index, body mass index or Benn index? Ann Hum Biol. 1997 Jul-Aug; 24(4):289-98.

\section{How to cite this article?}

Geetha M., Kiran B., Santosh. S., Rangaiah V., Himabindu T., Pavan Raj, Angel L.D. CAN score- a boon to resource limited settings. Int J Pediatr Res. 2019;6 (04):189-193. doi:10.17511/ijpr.2019.i04.07 